\title{
Five-Point Algorithm Solution with Initial value Estimation and Non-Linear Least Square Optimization
}

\author{
織田 和夫* \\ Kazuo ODA
}

\begin{abstract}
This paper proposes five-point algorithm with initial value estimation and non-linear least square optimization. Five-point algorithm is a powerful method for relative orientation because it requires no initial assumption of camera position and attitude. This algorithm algebraically calculates an essential matrix from five point correspondences between two calibrated cameras. However, a result of five-point algorithm includes multiple solutions and some selecting process must be executed. The method proposed here tries to calculate the appropriate essential matrix with non-linear optimization with appropriate initial values, which is obtained with additional 3 pairs of corresponding points. In this paper the relationship between traditional parametric relative orientation and essential matrix is discussed, and after that five-point algorithm with non-linear least square optimization is introduced.
\end{abstract}

\section{1.はじめに}

5 点法（five point algorithm）は，ステレオ画像間 の 5 点の対応点を用いて相互標定要素を代数的に求め る手法であり, Structure From Motion で画像の相対 位置の初期值を求める上で重要な手法である。Structure From Motionでは相互標定要素は基本行列 （Essential Matrix）で表現され，相互標定要素と相互 に変換が可能である11。

5 点法はカメラの方向が収斂していたり，一方の撮 影位置がもう一方の画像に含まれていたりするような 特殊なケースでも解を得ることができ，初期值が未知 の状態で解を得ることができるということで超越方程 式を非線形最小二乗法で解く伝統的な相互標定手法よ り優れている。ただし，実際の点の観測には誤差が含 まれているため，誤差評価ができない。すなわち，得 られた解は観測誤差の影響をそのまま受けることにな る。その意味で, 5 点法の解は最小二乗解を得るため の初期值を与える手法であると言える。

*アジア航測株式会社

「写真測量とリモートセンシング」VOL. 53，NO. 6， 2014
5 点法の解法としては, 完全に代数的に解く手 法2)314) と, 非線形最小二乗法を利用する手法5)がある。 代数的に解く場合は，スケール倍の任意性を除いて 3 変数 3 次連立方程式を解く必要がある。Stewénius ら ${ }^{31}$ は Groebner 基底を用いて解く方法を提案してい る。また $\mathrm{Li} \mathrm{ら}{ }^{4}$ は 3 次連立方程式を一つの変数とのこ り 2 つの変数の積に分解し, 前者の行列式が 0 になる ことを利用して10次方程式を導出し，これを解いてい る。いずれの方法も最大 $10 の$ 多重解を持つことになり, これから実際の解を他の対応点を利用して検証し求め ることが必要となる。実際，5点の共面条件を満たす カメラの幾何学的配置は 1 つとは限らない1)。

一方, Batra ら ${ }^{5}$ は高次方程式を数值的に解く際の 不安定性を指摘し, 別の方法として非線形最小二乗法 を適用して基本行列を求好手法を提案している。非 線形最小二乗法においては初期值の推定が必要になる が，ここでは試行錯誤的に求めている。Rodehorst ら ${ }^{6)}$ の比較研究によると, この方法は正しい解に収束しな い場合が多い。 5 点法に非線形最小二乗法を適用する には，ある程度正しい初期值を与える必要がある。

本論文では非線形最小二乗法を適用する 5 点法の新 しい手法を提案する。ここでは 5 点法に 8 点法を組み 合わせることにより, 適切な初期值を与え非線形最小 
二乗法を解く。

本論文では, 初期值推定をまず基本行列と超越方程 式による共面条件との関係性を論じる。また，基本行 列は実数倍の任意性があるが，己れを正規化する方法 について提案する。

続いて従来の代数的に解く 5 点法と問題点を述べた のち， 5 点法に 8 点法を組み合わせることにより, 適 切な初期值を与え非線形最小二乗法を解くことが可能 であることを数值実験の結果を交えて示す。数值実験 においては, 非線形最小二乗法として LevenbergMarquardt 法 (LM 法) と, Gauss-Newton 法の両方 を比較した。

\section{2. 相互標定パラメータと基本行列の関係}

\section{1 共面条件と基本行列}

共面条件は, 2 つのカラの投影中心と, 撮像面上 の対応点位置が同一平面上にあることを示す。すなわ ちカメラ 1 とカメラ 2 の投影中心を $O_{1}\left(X_{01}, Y_{01}, Z_{01}\right)$ および $O_{2}\left(X_{02}, Y_{02}, Z_{02}\right)$, 各カメラの対応点の撮像面上 の座標を $P_{1}\left(X_{1}, Y_{1}, Z_{1}\right)$ および $P_{2}\left(X_{2}, Y_{2}, Z_{2}\right)$ とする と, 共面条件は次の式で記述される。

$\left|\begin{array}{cccc}X_{01} & Y_{01} & Z_{01} & 1 \\ X_{02} & Y_{02} & Z_{02} & 1 \\ X_{1} & Y_{1} & Z_{1} & 1 \\ X_{2} & Y_{2} & Z_{2} & 1\end{array}\right|=0$

一方共面条件は, $\overrightarrow{O_{1} O_{2}}, \overrightarrow{O_{1} P_{1}}, \overrightarrow{O_{2} P_{2}}$ のベクトル三 重積（三つのベクトルを辺とする平行四面体の体積） でも表現できる。ベクトルの外積を「メ」，内積を「・」 で表すとすると，

$\left(\overrightarrow{O_{1} O_{2}} \times \overrightarrow{O_{1} P_{1}}\right) \cdot \overrightarrow{O_{2} P_{2}}=0$

式(1)および式(2)は展開すると同一の条件であることが 確認できる。

基本行列は, 式(2)を用いて 2 つのカメラ座標の関係 を与えるものである。すなわち，基準となる座標系に 対するカメラ 1 の座標系を基準とし, $\overrightarrow{O_{1} O_{2}}=\left(b_{x}, b_{y}\right.$, $\left.b_{z}\right)$, 基準系に対するカメラ 2 のカメラ座標系の回転行 列を $R_{2}$, 各カメラの対応点の撮像面上のカメラ座標を $p_{1}\left(x_{1}, y_{1},-c_{1}\right)$ および $p_{2}\left(x_{2}, y_{2},-c_{2}\right) \quad\left(c_{1}\right.$ と $c_{2}$ は画面 距離) とすると, $\left(x_{1}, y_{1},-c_{1}\right) \times\left(b_{x}, b_{y}, b_{z}\right) \cdot R_{2} \cdot\left(\begin{array}{c}x_{2} \\ y_{2} \\ -c_{2}\end{array}\right)=0$

ここで,

$$
\begin{aligned}
& \left(x_{1}, y_{1},-c_{1}\right) \times\left(b_{x}, b_{y}, b_{z}\right)= \\
& \quad\left(x_{1}, y_{1},-c_{1}\right) \cdot\left(\begin{array}{ccc}
0 & -b_{z} & b_{y} \\
b_{z} & 0 & -b_{x} \\
-b_{y} & b_{x} & 0
\end{array}\right)
\end{aligned}
$$

とかけるので，共面条件は

$\left(x_{1}, y_{1},-c_{1}\right) \cdot\left(\begin{array}{ccc}0 & -b_{z} & b_{y} \\ b_{z} & 0 & -b_{x} \\ -b_{y} & b_{x} & 0\end{array}\right) \cdot R_{2} \cdot\left(\begin{array}{c}x_{2} \\ y_{2} \\ -c_{2}\end{array}\right)=0$

となる。 $3 \times 3$ の行列

$E=\left(\begin{array}{ccc}0 & -b_{z} & b_{y} \\ b_{z} & 0 & -b_{x} \\ -b_{y} & b_{x} & 0\end{array}\right) \cdot R_{2}$

を基本行列と呼ぶ。すなわち，2つのカメラ座標と基 本行列は次の式で関係付けられる。

$\left(x_{1}, y_{1},-c_{1}\right) \cdot E \cdot\left(\begin{array}{c}x_{2} \\ y_{2} \\ -c_{2}\end{array}\right)=0$

なお，基本行列は実数倍しても共面条件は成立するの で，実数倍の任意性がある。

回転行列 $R$ を

$R(\varkappa, \varphi, \omega)=$

$\left(\begin{array}{ccc}1 & 0 & 0 \\ 0 & \cos \omega & -\sin \omega \\ 0 & \sin \omega & \cos \omega\end{array}\right)\left(\begin{array}{ccc}\cos \varphi & 0 & \sin \varphi \\ 0 & 1 & 0 \\ -\sin \varphi & 0 & \cos \varphi\end{array}\right)\left(\begin{array}{ccc}\cos \varkappa & -\sin \varkappa & 0 \\ \sin \varkappa & \cos \varkappa & 0 \\ 0 & 0 & 1\end{array}\right)$

と定義し, また, $\overrightarrow{O_{1} O_{2}}=\left(b_{x}, 0,0\right)$ となる座標系を基準 とし,

$T=\left(\begin{array}{ccc}0 & 0 & 0 \\ 0 & 0 & -b_{x} \\ 0 & b_{x} & 0\end{array}\right)$

とおくと, 基本行列は次の式であらわされる。 
$E\left(\chi_{1}, \varphi_{1}, \omega_{1}, \chi_{2}, \varphi_{2}, \omega_{2}\right) \cong$

$$
R_{1}{ }^{T} \cdot T \cdot R_{2}=R\left(\varkappa_{1}, \varphi_{1}, \omega_{1}\right)^{T} T \cdot R\left(\varkappa_{2}, \varphi_{2}, \omega_{2}\right)
$$

ここでミは実数倍すれば等しくなることを意味し， $\chi_{1}$, $\varphi_{1}, \omega_{1}$ および $\chi_{2}, \varphi_{2}, \omega_{2}$ はカメラ 1 とカメラ 2 の回転 パラメータである。

\section{2 基本行列の性質}

\subsection{1 基本性質 1}

基本行列の行列式は 0 である。すなわち

$\operatorname{det}(E)=0$

これは $\operatorname{det}(T)=0$ より明らかである。

\section{2 .2 基本性質 2}

基本行列は次の 3 次の拘束をみたすことが必要十分 条件である5

$2\left(E \cdot E^{T}\right) \cdot E-\operatorname{tr}\left(E \cdot E^{T}\right) \cdot E=0$

\subsubsection{X 軸周りの回転に関する任意性}

$$
\begin{aligned}
& E\left(\varkappa_{1}, \varphi_{1}, \omega_{1}, \chi_{2}, \varphi_{2}, \omega_{2}\right) \cong \\
& \quad E\left(\chi_{1}, \varphi_{1}, \omega_{1}+\omega, \chi_{2}, \varphi_{2}, \omega_{2}+\omega\right)
\end{aligned}
$$

が成立する。すなわち基本行列を決定するのは実質 5 つの角度となり， $\omega_{1}=0$ とおいても問題ない。

\subsection{4一つの基本行列に関する任意性}

異なる回転行列が同じ基本行列に対応するケースが 存在するので注意する必要がある。

(1) $E\left(\varkappa_{1}, \varphi_{1}, 0, \varkappa_{2}, \varphi_{2}, \omega_{2}\right) \cong$

$$
E\left(\varkappa_{1}, \varphi_{1}, 0, \chi_{2}, \varphi_{2}, \omega_{2}+\pi\right)
$$

(2) $E\left(\varkappa_{1}, \varphi_{1}, 0, \chi_{2}, \varphi_{2}, \omega_{2}\right) \cong$

$$
E\left(\chi_{1}, \varphi_{1}+\pi, 0, \chi_{2}^{\prime}, \varphi_{2}^{\prime}, \omega_{2}^{\prime}\right)
$$

$$
\text { ただし } R\left(\varkappa_{2}^{\prime}, \varphi_{2}^{\prime}, \omega_{2}^{\prime}\right)=R(0, \pi, 0) \cdot R\left(\varkappa_{2}, \varphi_{2}, \omega_{2}\right)
$$

(3) $E\left(\varkappa_{1}, \varphi_{1}, 0, \varkappa_{2}, \varphi_{2}, \omega_{2}\right) \cong$

$$
E\left(\varkappa_{1}+\pi,-\varphi_{1}, 0, \chi_{2}^{\prime}, \varphi_{2}^{\prime}, \omega_{2}^{\prime}\right)
$$

ただし $R\left(\varkappa_{1}+\pi,-\varphi_{1}, 0\right)=R\left(\chi_{1}, \varphi_{1}+\pi, \pi\right)$ であり, $\mathrm{X}$ 軸周りの任意性を考慮すると (2)と(3)幾何学的には同 一とみなすことができる。実際には(1)と(2)の組み合わ せによる 4 つのケースを考慮する必要がある。Hartley ${ }^{7)}$ や服部息が指摘しているように，カメラの前面で 交会するものはその中の 1 つだけなので，これらから
適切なものを決定することが可能である。

\section{3 基本行列の正規化}

基本行列は実数倍の任意性を持つが，異なる基本行 列で共面条件を評価する際，共面条件で計算する四面 体の体積は $b_{x}$ に比例するため, 共通のスケールをもつ 基本行列で評価することが望ましい。例えば, Stewénius ら $\left.{ }^{3)} \mathrm{Li}^{4}\right)$ らは正解の基本行列と計算され た基本行列を比較するため, フロベニウスのノルムに よる正規化を行っている。

$E n=E /\|E\|$

ここで $\|E\|$ は行列 $E$ のフロベニウスのノルムであり, 次の式で定義される。

$\left\|\left(\begin{array}{lll}a_{11} & a_{12} & a_{13} \\ a_{21} & a_{22} & a_{23} \\ a_{31} & a_{32} & a_{33}\end{array}\right)\right\|=\sqrt{\sum_{i=1}^{3} \sum_{j=1}^{3} a_{i j}}$

$$
=\sqrt{\operatorname{trace}\left(\begin{array}{lll}
a_{11} & a_{12} & a_{13} \\
a_{21} & a_{22} & a_{23} \\
a_{31} & a_{32} & a_{33}
\end{array}\right)\left(\begin{array}{lll}
a_{11} & a_{12} & a_{13} \\
a_{21} & a_{22} & a_{23} \\
a_{31} & a_{32} & a_{33}
\end{array}\right)^{T}}
$$

この正規化によって $E n$ のフロベニウスのノルムは 1 に調整される。

一方，基本行列のフロベニウスのノルムは対角和が 相似な変換に対して不変であることを利用すると

$$
\begin{aligned}
\|E\|^{2} & =\operatorname{tr}\left(E \cdot E^{T}\right) \\
& =\operatorname{trace}\left(R_{1}{ }^{T} \cdot\left(T \cdot T^{T}\right) \cdot R_{1}\right) \\
& =\operatorname{trace}\left(T \cdot T^{T}\right) \\
& =\operatorname{trace}\left(\begin{array}{ccc}
0 & 0 & 0 \\
0 & b_{x}{ }^{2} & 0 \\
0 & 0 & b_{x}{ }^{2}
\end{array}\right)=2 b_{x}{ }^{2}
\end{aligned}
$$

である。すなわち，Enは $b_{x}$ が $1 / \sqrt{2}$ もしくは $-1 / \sqrt{2}$ を持つケースである。

織田 ${ }^{1}$ は $b_{x}=1$ (もしくは $b_{x}=-1$ と)，すなわちフロ ベニウスのノルムが 2 になるものを正規化基本行列 $\left(E_{N}\right)$ と呼ぶことを提案している。式(18)を用いると正規 化基本行列は次の式で表現できる。

$E_{N}=\sqrt{2 / \operatorname{tr}\left(E \cdot E^{T}\right)} \cdot E$ 


\section{3. 従来の 5 点法}

基本行列は 3 行 3 列の行列なので 9 つの未知数があ るが， 5 つの対応点の共面条件式を用いると，9元 1 次方程式を 5 つ立てることができる。基本行列 $E$ を

$E=\left(\begin{array}{lll}a_{11} & a_{12} & a_{13} \\ a_{21} & a_{22} & a_{23} \\ a_{31} & a_{32} & a_{33}\end{array}\right)$

とおくと, 式(6)で与えられる共面条件は, $a_{11} \sim a_{33}$ の 9 つの係数の一次方程式となる。

$x_{1} x_{2} a_{11}+x_{1} y_{2} a_{12}-x_{1} c_{2} a_{13}+y_{1} x_{2} a_{21}+y_{1} y_{2} a_{22}$

$-y_{1} c_{2} a_{23}-c_{1} x_{2} a_{31}-c_{1} y_{2} a_{32}+c_{1} c_{2} a_{33}=0$

今, 5 つの対応点 $\left(x_{1 m}, y_{1 m}\right),\left(x_{2 m}, y_{2 m}\right)(m=1,2, \cdots, 5)$ が与えられ，それぞれの対応関係で共面条件を構成す ると 4 つの 9 元 1 次方程式が得られる。

$A \cdot\left(a_{11}, a_{12}, a_{13}, a_{11}, a_{22}, a_{23}, a_{31}, a_{32}, a_{33}\right)^{T}=0$

ここで $A$ は 5 行 9 列の係数行列である。この式によっ て未知数を 4 つに減らすことができる。未知数を減ら すにあたっては, 上記の 5 行 9 列の係数行列 $A$ を特異 值分解して得られる零空間を利用する2)314)。行列 $A$ を 特異值分解寸ると, 5 行 5 列の直交行列 $U$ と 9 行 9 列 の直交行列 $V$ を用いて連立方程式は以下のようにあ らわされる。

$U \cdot\left(\begin{array}{ccccccccc}t_{1} & 0 & 0 & 0 & 0 & 0 & 0 & 0 & 0 \\ 0 & t_{2} & 0 & 0 & 0 & 0 & 0 & 0 & 0 \\ 0 & 0 & t_{3} & 0 & 0 & 0 & 0 & 0 & 0 \\ 0 & 0 & 0 & t_{4} & 0 & 0 & 0 & 0 & 0 \\ 0 & 0 & 0 & 0 & t_{5} & 0 & 0 & 0 & 0\end{array}\right) \cdot V \cdot\left(\begin{array}{c}a_{11} \\ \vdots \\ a_{33}\end{array}\right)=0$

(23)

行列 $V$ を

$V=\left(\begin{array}{llllllllll}V_{1} & V_{2} & V_{3} & V_{4} & V_{5} & V_{6} & V_{7} & V_{8} & V_{9}\end{array}\right)^{T} \quad(24)$

とおき， $V_{1} \sim V_{9}$ は互いに直交することを考慮すると， $V_{6}, V_{7}, V_{8}, V_{9}$ の 4 つは上記方程式の線形独立な解, すなわち零空間を構成する。 $V_{6}, V_{7}, V_{8}, V_{9}$ をそれぞ れ（3 行 3 列）の行列に並べ替えたものを $\chi_{1} \cdots \chi_{4}$ とお くと, 基本行列 $E$ は下記のように 4 つの未知数による 線形結合で表現できる。
$E=\sum_{i=1}^{4} \alpha_{i} \chi_{i}$

実際には $E$ は実数倍の任意性を持つので, 上記の 4 つの内の一つを固定 (たとえば $\alpha_{4}=1$ ) することにより 未知数を 3 つに減らすか, 実数倍の任意性をなくすた めの別の拘束式を扔くことが多い。

基本行列であるためには, 式(11)を満たすことが必要 十分である。この式に式(25)を代入すると， $\alpha_{i}$ に関する 9 つの 3 次方程式が得られる。Stewénius ら ${ }^{3)} \mathrm{Li}^{4}$ ら の 5 点法はこれに加えて基本行列の行列式が 0 である 条件（式(10)）とともに 10 個の 3 元 3 次連立方程式を立 て，これを代数的に解いている。これは最終的には 1 元10次方程式に帰着され最大 10 個の実数解が得られ る。なお，式(11)を満たす行列 $E$ は必ず $\operatorname{rank}(E)<3$ な ので, 必ず式(10)を満たす。式(10)を加えるのは, 高次連 立方程式を解くための便宜のためである。織田 ${ }^{1}$ が指 $^{-}$ 摘するように幾何学的にも代数的に求めた 5 点法の解 は複数存在する場合がある。

Batra ら ${ }^{5}$ は上記 4 つの未知数に加えて 2 つのカメ ラ間ベクトル成分を含めた 7 つの未知数を， 2 次式の 拘束に帰着させ, これを非線形最小二乗法で解いている。

\section{4. 初期值推定を伴う非線形最小二乗法に よる 5 点法の解法}

非線形最小二乗法で解く場合は, いくつかの初期值 を準備し他の点を検証する必要がある。本論文では, 追加で 3 点もしくはそれ以上の対応点情報を利用して 未知数の初期值を求め, これを初期值として最小二乗 法で解くことを提案する。

5 点の対応点を与えた上で基本行列を式(25)で表現す る。ここで 4 つの係数 $\alpha_{i}$ すべてを未知数とする。また 実数倍の任意性を固定するため基本行列が正規化基本 行列 $E_{N}$ であるよう拘束を加之る。この拘束は次の式 であらわされる。

$\left\|E_{N}\right\|-2=0$

(26)

さらに，式(11)で表現される基本行列であることの必要 十分条件は

$\left(E_{N} \cdot E_{N}^{T}\right) \cdot E_{N}-E_{N}=0$

となる。式(26)㧍よび(27)は10個の連立方程式を構成する。

ここで提案する手法は, 式(26)で得られる 2 次式およ 
び式(27)の左辺で得られる 9 つの 3 次式の誤差の二乗和 が 0 となるように非線形最小二乗法を適用し，4つの 未知の係数 $\alpha_{i}$ を決定する。この際, 最初に与えた 5 点 以外の 3 点の対応点と式(20)で表現される基本行列を用 いて得られる 3 つの共線条件抒よび式(21)の実数倍決定 条件を用いて 4 つの未知の係数 $\alpha_{i}$ の初期值を求める。 最初に $\alpha_{4}=1$ として残りの 3 つの係数の連立一次方程 式を解くことによってもとめ, これで得られた行列が 式(26)を満たすよう改めて係数 $\alpha_{i}$ を再決定する。その後 は非線形最小二乗法で以下の式を満たす最適解を求め る。

$\min \sum_{i=1}^{10}\left(P_{N}\right)^{2}$

ここで $P_{N}$ は式(26)および式(27)の左辺を示す。ただし これでは式(26)を厳密に満たさないので, 繰り返し計算 ごとに式(26)を満たすよう係数を再調整する。

なお, すべての点が平面上に存在するとき, 対応点 の座標は射影変換 (Homography) になる。このとき, 8 点法は行列式が 0 となり本手法では正しく初期值を 求めることができない。このような場合は初期值をう ンダムに与えることとし，収束計算を行う。収束しな い場合は収束するまで制限回数までリトライすること とする。

\section{5. 数值実験}

\section{1 起伏のある点配置の場合}

前章で提案した手法に関してシミュレーションデー 夕を用いた数值実験を行った。数值実験は下記に示す 設定で行った。実験では画像座標の䛊差はないものと した。

数值実験は計測点配置 (10通り) と起伏率 ( 5 通り) の組み合わせで50回行った。また，非線形最小二乗法 として, Levenberg-Marquardt 法(LM 法) と, Gauss -Newton 法を比較した。なお, Levelberg-Marquardt 法と Gauss-Newton 法については直接コーディング したものを使用した。線形代数モジュールについては OpenCV ${ }^{9}$ を使用した。 Levelberg-Marquardt 法では, 最急降下法のための係数の初期值を 1 とし, 収束した 場合は $1 / 10$ 倍，収束しない場合は 10 倍と制御した。

また，計算された正規化基本行列の精度を下記の式 で評価した。
表 1 数值実験におけるカメラおよび計測点位置の設定

\begin{tabular}{|l|l|}
\hline カメラ間距離 & $1 \mathrm{~m}$ \\
\hline カメラ方向 & $\begin{array}{l}\varkappa:-\pi \sim \pi \text { でランダムに設定 } \\
\phi \cdot \omega:-\pi / 4 \sim \pi / 4 \text { でランダムに設定 }\end{array}$ \\
\hline $\begin{array}{l}\text { (計測点配置 } \\
\text { ( ) }\end{array}$ & $\begin{array}{l}1 \mathrm{~m} \times 2 \mathrm{~m} \text { の矩形に } 8 \text { 点配置 } \\
\text { (矩形までの距離 } \mathrm{D} \text { は } 1 \mathrm{~m} \sim 10 \mathrm{~m} \text { の } 10 \text { 通 } \\
\eta)\end{array}$ \\
\hline 起伏率 & $\begin{array}{l}\text { 矩形上の起伏の標準偏差 } \sigma \text { を距離 } \mathrm{D} \times \mathrm{R} \\
\text { に設定 } \\
(\mathrm{R}=0.1,0,01 \cdots 0.00001 の 5 \text { 通り) }\end{array}$ \\
\hline 画像座標誤差 & なし \\
\hline
\end{tabular}

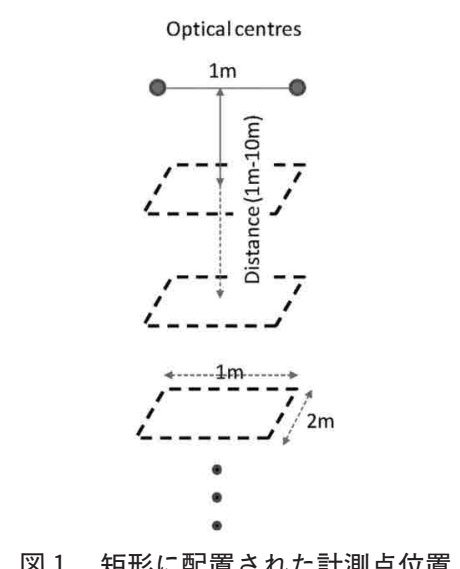

図 1 矩形に配置された計測点位置

$e_{E_{N}}=\min \left(\left\|\widehat{E_{N}}-E_{N}\right\|,\left\|\widehat{E_{N}}+E_{N}\right\|\right)$

ここで $\widehat{E_{N}}$ は真の正規化基本行列である。

比較のため, Stewénius らの手法で同じデー夕に ついて計算し, 比較を行った。Stewénius らろの手法に よる計算は Bundler ${ }^{10111)}$ に実装されているものを利用 した。

図 2 は誤差の $\log 10$ と矩形までの距離 D との関係を 示す。それぞれの距離のデータは 5 通りの異なる起伏 の平均を示す。図より, 本手法で計算された正規化基 本行列の方が Stewénius らの手法で計算したものよ り 1 ～ 2 オーダー精度よく計算されていることが分か る。これは, Batra ら゙)が指摘しているとおり, 高次方 程式を解く際の不安定性に起因すると推定する。

図 2 より, 計測点までの距離が遠いほど精度が悪く なる傾向があることが分かる。これは, 計測点の占め る視野角が距離が遠いほど小さくなるからであると解 釈される。Nisterの手法では $1 \mathrm{~m}$ と $10 \mathrm{~m}$ を比較すると 


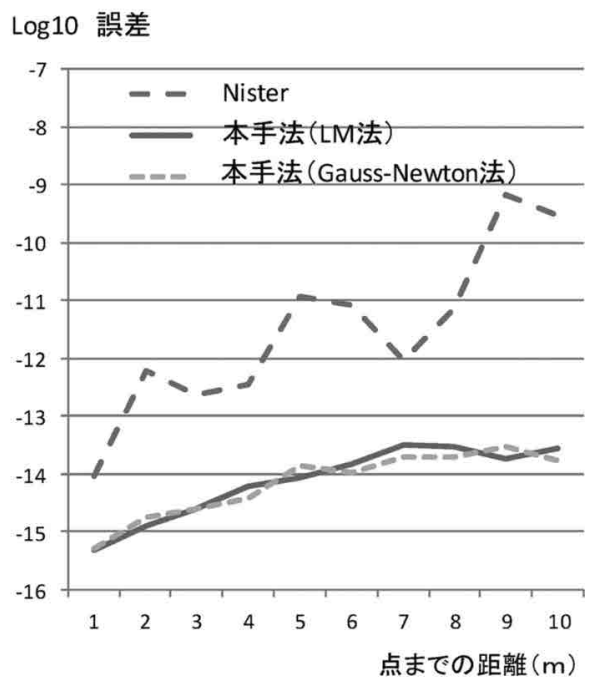

図 $2 \log 10$ 誤差 (起伏のある点配置)

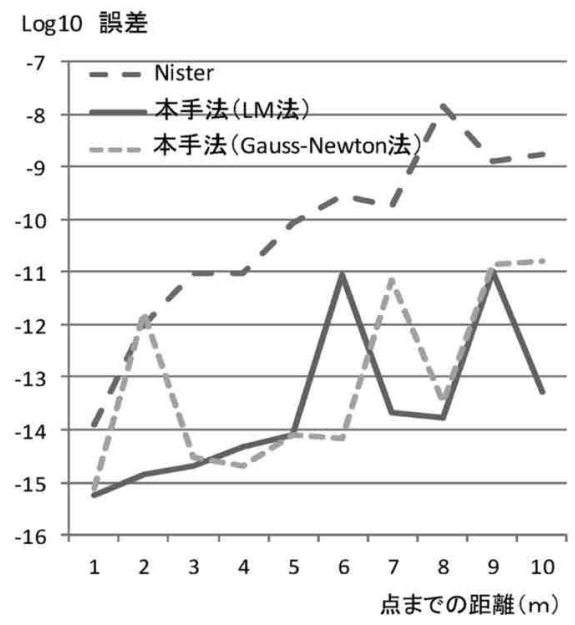

図 $3 \log 10$ 誤差

(平面上に配置されている場合)

表 2 平面上に配置されている場合の収束状況

4 オーダーほどの精度の悪化が見られるが，本手法で は 1 ～ 2 オーダーの悪化にとどまっている。

このテストでは，すべてのケースについて初期值が 計算でき，すべてが正しく収束した。これは初期值の 計算が正しく行えたことを示している。また，LM 法 と, Gauss-Newton 法を比較してみると, 再者はほと んど変わらない結果となった。

\section{2 平面上に点が配置されている場合}

比較実験として，平面上に点が配置されている場合 についても実験を行った。ここでは起伏率を 0 とし， それぞれの計測点配置（10通り）について 5 回ずつ, 計 50 回行った。またりトライの最大回数を 20 回とした。

図 3 は誤差の $\log 10$ と矩形までの距離 D との関係を 示す。全体の傾向は図 2 と同様であるが，本手法で局 所的に精度が悪くなっていることが分かる。これは， 計算が収束しなかった場合や誤った值に収束した場合 があるためである。

表 1 に LM 法と, Gauss-Newton 法の収束状況を示 す。どちらも $90 \%$ 以上が正しい值に収束したが, Gauss -Newtonの場合は間違った值に収束する場合が見ら れた。平均リトライ回数は LM 法で5.64回, GaussNewton 法で4.24回であった。わずかであるが LM 法 の方が Gauss-Newton 法より正しい結果に収束する 割合が高かった。

LM 法・Gauss-Newton 法いずれの場合も，間違つ

\begin{tabular}{|l|r|r|}
\hline & \multicolumn{1}{|c|}{ LM 法 } & Gauss-Newton 法 \\
\hline 収束 & $48 / 50(96 \%)$ & $50 / 50(100 \%)$ \\
\hline 正しい值に収束 & $48 / 50(96 \%)$ & $46 / 50(92 \%)$ \\
\hline 間違った值に収束 & $0 / 50(0 \%)$ & $4 / 50(8 \%)$ \\
\hline 平均リトライ回数 & 5.64 & 4.24 \\
\hline
\end{tabular}

た值に収束しているケースが見られるが，式(28)で定義 される最小二乗和は十分小さくなっており, 別の解に 収束したと考えられる。これは次のようなケースであ る。図 4 において, $R_{1}=R_{2}=R(0,0,0), O_{1}=(0,0,0)$, $\mathrm{O}_{2}=(1,0,0)$, 画面距離を 1 とし, 観測点の三次元座標 を $P_{1}(0,0,-1) \cdot P_{2}(0,1,-1) \cdot P_{3}(0,-1,-1) \cdot P_{4}(1,0$, $-1) \cdot P_{5}(1,1,-1)$ とする。各点のカメラ座標は, カメラ 1 に打いて $p_{11}(0,0,-1) \cdot p_{12}(0,1,-1) \cdot p_{13}(0,-1$, $-1) \cdot p_{14}(1,0,-1) \cdot p_{15}(1,1,-1)$, カメラ 2 において $p_{21}(-1,0,-1) \cdot p_{22}(-1,1,-1) \cdot p_{23}(-1,-1,-1) \cdot p_{24}(0,0$, $-1) \cdot p_{25}(0,1,-1)$ である。

2 つのカメラを図のように $\mathrm{Y}$ 軸周りに回転する。こ の時, $\mathrm{Y}$ 軸方向から見て直角二等辺三角形の 2 つの角 の Z 座標が土で同じ值となるような角度とする。この 時, 変換後の座標の対応する点の Z 座標は全ての点で 一致する。また Y 軸周りの回転なので対応する全ての 点で $\mathrm{Y}$ 座標も一致する。すなわち, 対応する点を結ぶ 直線は $\overrightarrow{O_{1} O_{2}}$ に平行となる。よってすべての対応点に おいて共面条件が成立する。 


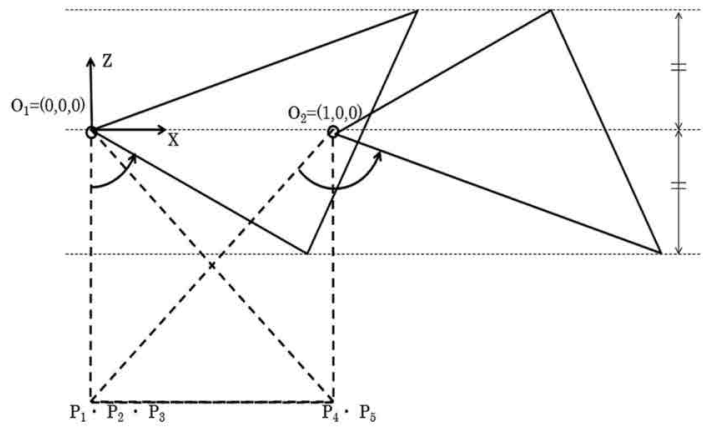

図 45 点法の多重解の例

\section{6.まとめ}

本論文では, 非線形最小二乗法による 5 点法の解法 を示した。正しい収束解を求めるため， 8 点法を援用 して初期值を求め, 収束計算を行った。画像座標の誤 差がないとした数值実験において, Nisterの手法より

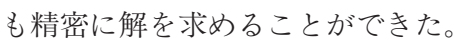

すべての点が平面上に分布する場合，本手法の初期 值計算は失敗するが，そのような場合はランダムに初 期值を与えることにより $90 \%$ 以上のケースにおいて正 しい解に収束することが分かった。

また非線形最小二乗法の実装方法として LM 法と, Gauss-Newton 法を比較したが，両者において大きな 違いは見られなかった。

今後は画像座標の誤差が本手法にどの程度影響する かを考察する必要がある。また今回はカメラの投影中 心が他のカメラに写っているようなケースについては シミュレーションを行わなかったので，今後そのよう なケースについても検討を行いたい。

5 点法は自由度が 0 のため観測值に誤差が含まれる 場合の誤差評価が行えない。より正しい相互標艇を行 うためには 5 点法で求めた初期值を用いて従来の 5 つ の相互標定要素を非線形最小二乗法で求める手法で精 密な解を求めることが必要である。一方 5 点法は平行 ではない撮影方法（カメラの方向や撮影スケールが大 きく異なる場合）でも解を得ることができる強力な相 互標定手法であり，5点法を用いた解を書機会にする ことで相互標定を安定かつ精密に行うことができるよ うになる。その意味で, 今後観測值に誤差を含む場合 を検討するに当たっては, 従来方法との組み合わせで
安定した解が得られるかを検討することにより実用的 な実装が行えるようになると考える。

(受付日2014.9.12，受理日2014.11.10)

\section{参考文献}

1 ) 織田和夫，相互標定とエッセンシャル行列に関す る考察, 日本写真測量学会平成 24 年度秋季学術講演 会発表論文集，pp.125-126，2012.

2 ) D. Nister : An efficient solution to the fivepoint relative pose problem, IEEE Trans. on Pattern Analysis and Machine Intelligence 26(6), pp.756-777, 2004.

3 ) Stewénius, H., Engels, C. and Nistér, D., 2006. Recent developments on direct relative orientation, ISPRS Journal of Photogrammetry and Remote Sensing, vol. 60, no. 4, pp.284-294, 2006.

4) H. Li, R. Hartley: Five-Point Motion Estimation Made Easy, ICPR (1), pp.630-633, 2006.

5 ) D. Batra, B. Nabbe, M. Hebert: An alternative formulation for five point relative pose problem, IEEE Workshop on Motion and Video Computing WMVC '07, 2007.

6 ) Rodehorst, V., Heinrichs, M., and Hellwich, O., 2008. Evaluation of relative pose estimation methods for multi-camerasetups. The International Archives of the Photogrammetry, Remote Sensing and Spatial Information Sciences, Vol. XYXXVII, Part B3b, Beijing, 2008.

7 ) R. Hartley, A. Zisserman: Multiple View Geometry in computer vision, Cambridge University Press, second edition, 2003.

8 ）服部 進, 関 章良, バンドル調整のための外部 標定要素の近似值の自動計算法, 土木学会論文集, No. 646, IV-19, pp.139-147, 1993.

9 ) http://opencv.org/ (accessed 15 Oct. 2014).

10) http://www.cs.cornell.edu/ snavely/bundler/\# S4 (accessed 15 Oct. 2014).

11) Noah Snavely, Steven M. Seitz, Richard Szeliski, "Photo tourism: Exploring photo collections in 3D," ACM Transactions on Graphics (SIGGRAPH Proceedings), 25(3), pp.835-846, 2006. 